\title{
Genetic Polymorphisms in the Vitamin D Pathway and Non-small Cell Lung Cancer Survival
}

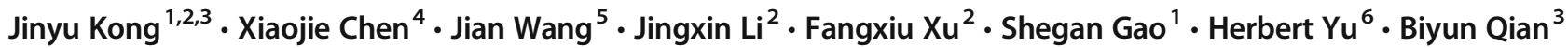

Received: 7 March 2019 / Accepted: 19 July 2019 / Published online: 17 October 2019

(C) The Author(s) 2019

\begin{abstract}
Various genetic polymorphisms have been linked to lung cancer susceptibility and survival outcomes. Vitamin D (VD) regulates cell proliferation and differentiation, inhibits tumor growth and induces apoptosis. Observations from several previous studies including our own suggest that genetic polymorphisms in the VD pathway may be associated with lung cancer risk. The aim of this study is to assess if genetic polymorphisms in the VD pathway are associated with the prognosis of non-small cell lung cancer (NSCLC). Nine single nucleotide polymorphisms (SNPs) in five genes in the VD pathway were genotyped with the TaqMan assays in 542 patients with primary NSCLC, and the relationships between these SNPs and overall survival were evaluated. We found that SNP rs10741657 in the CYP2R1 gene was associated with the prognosis of NSCLC, especially in elderly patients and not being treated with chemotherapy. Some of the VD pathway-related genetic polymorphisms may influence the prognosis of NSCLC. More research is needed to further confirm the finding and test if VD supplements can be used for NSCLC treatment.
\end{abstract}

Keywords Non-small cell lung cancer $\cdot$ Vitamin D pathway $\cdot$ Single nucleotide polymorphism $\cdot$ Genetic susceptibility $\cdot$ Prognosis

\section{Introduction}

Non-small cell lung cancer (NSCLC) is a major form of malignancies in the lung and a leading cause of cancer deaths in the world $[1,2]$. Despite advances in the diagnosis and treatment of NSCLC in recent decades, the prognosis for patients is still poor compared with the other cancers, such as breast, prostate, and colorectal, especially in China, with the 5-year survival rate of less than $20 \%$ [3]. This difference is attributed to variations in the biology of lung tumors [4]. Therefore, the identification of novel biomarkers for more precise prognostication in NSCLC patients would be very important .

Vitamin D (VD) has many important biologic functions, including control of cell proliferation, regulation of differentiation, inhibition of tumor growth and induction of apoptosis [5-7]. The protective effects of VD against lung cancer have been suggested $[8,9]$. The biologic actions of VD and other molecules which transport and mediate its effects are achieved through a series of biochemical reactions which convert a VD precensors to a bioactive VD. The process is catalyzed by a

Jinyu Kong and Xiaojie Chen contributed to this work equally.

Biyun Qian

qianbiyun@shsmu.edu.cn

1 Henan Key Laboratory of Cancer Epigenetics; Cancer Institute, The First Affiliated Hospital, and College of Clinical Medicine of Henan University of Science and Technology, Luoyang 471003, China

2 Department of Cancer Epidemiology and Biostatistics, National Clinical Research Center of Cancer, Key Laboratory of Cancer Prevention and Therapy, Tianjin Medical University Cancer Institute and Hospital, Tianjin 300060, China
3 Hongqiao International Institute of Medicine, Shanghai Tongren Hospital and Faculty of Public Health, Shanghai Jiao Tong University School of Medicine, 227 South Chongqing Road, Shanghai 200025, China

4 Medical College, Henan University of Science and Technology, Luoyang 471003, Henan, China

5 Department of Image Diagnoses, The First Affiliated Hospital, and College of Clinical Medicine, Henan University of Science and Technology, Luoyang 471003, China

6 Epidemiology Program, University of Hawaii Cancer Center, 701 Ilalo Street, Honolulu, HI 96813, USA 
number of metabolizing enzymes, including 25-hydroxylases (CYP2R1 and CYP27A1) which convert pro-VD to 25hydroxyvitamin $\mathrm{D}_{3}\left[25(\mathrm{OH}) \mathrm{D}_{3}\right]$ and 1-alpha-hydroxylase (CYP27B1) which transforms $25(\mathrm{OH}) \mathrm{D}_{3}$ to a bioactive $\mathrm{VD}$, 1,25-dihydroxyvitamin $\mathrm{D}_{3}\left[1,25(\mathrm{OH})_{2} \mathrm{D}_{3}\right]$. Furthermorer, 25hydroxyvitamin D-24-hydroxylase (CYP24A1) involves VD degradation, vitamin D-binding protein (GC) facilitates VD transportation, and VD nuclear receptor (VDR) binds to $1,25(\mathrm{OH})_{2} \mathrm{D}_{3}$ exerting the biologic actions together with VD. Genes encoding cytochrome p450 enzymes (CYPs) are highly polymorphic, and therefore genetic polymorphisms related to the enzymes metabolising VD are speculated to affect VD activities, which may further influence the development and progression of lung cancer.

Although the relationship between polymorphisms in the VDR gene and lung cancer has been investigated recently [10], few studies have evaluated single nucleotide polymorphisms (SNPs) in the genes involved in the VD metabolism and activity in Chinese populations. Based on the results of a genome-wide association study (GWAS) [11] and analysis of bioinformatics data, our previous research selected several SNPs which are either potentially functional or known as tagSNPs in the CYP2R1, CYP27B1, CYP24A1, GC and VDR genes, and analyzed their genotypes in 1264 case and control subjects to determine their association with NSCLC. Associations of these SNPs with NSCLC risk have been discussed and several SNPs were found to be associated with the disease risk. We [10] and others [12] also found that expression of CYP27B1 and CYP2R1 differed by their genotypes in certain SNPs and the expression was associated with lung cancer survival. No studies have evaluated the possible effects of these SNPs on the prognosis of NSCLC. In this report, we discussed the results of our study which examined the relationships of SNPs involved in the VD pathway genes and the overall survival of NSCLC patients.

\section{Materials and Methods}

\section{Study Subjects}

Subjects in the study were recruited from Tianjin Medical University Cancer Hospital (TMUCH). Patients enrolled in the study were newly diagnosed between January 2006 and May 2011, and their diagnosis was histologically confirmed. Disease information on histological type, tumor size, lymph node metastasis, disease stage and treatments was extracted from patient medical records. Study patients were followed for survival outcomes from the date of diagnose to August 20, 2013 , or date of death due to recurrence, metastasis or other complications. Follow-up was achieved through clinical visits and regular telephone contacts. The study was approved by the ethical review committee at TMUCH. The methods were performed in accordance with the relevant guidelines and approved regulations. After signing an informed consent, all the participants in the study underwent a questionnaire-based inperson interview, and provided $10 \mathrm{ml}$ blood samples which were collected in an ethylene diamine tetraacetic acid (EDTA) vacutainer tube. Blood samples were processed immediately after collection. Plasma and buffy coats were separated after centrifugation at $2000 \mathrm{rpm}$ for $20 \mathrm{~min}$, and the specimens were stored in a liquid nitrogen tank until DNA extraction and genotyping.

\section{SNP Selection and Genotyping}

Based on information from the dbSNP database, HapMap and Haploview, we chose five major genes on the VD signaling pathway for our study, including CYP2R1, CYP27B1, CYP24A1, VDR, and GC. From these genes, we first identified tagging SNPs with linkage disequilibrium (LD) greater than 0.8 in the five selected genes plus the regions $100 \mathrm{~kb}$ upand downstream of each gene, and then selected SNPs located in the protein coding and promoter regions from the tagging SNPs with minor allele frequency $>5 \%$. A total of nine SNPs met our selection criteria. Of them, four SNPs are in CYP27B1 (rs3782130, rs4646536, rs703842, rs10877012), two in CYP24A1 (rs6068816, rs4809957), one in VDR (rs11574129), one in GC (rs7041), and one in CYP2R1 (rs10741657). Using the polymerase chain reaction (PCR)based florescence 5'nuclease assay (TaqMan), we genotyped these genetic polymorphisms in the blood of NSCLC patients. Detailed protocols for these TaqMan assays were described in our previous report [10].

\section{Statistical Analysis}

Log-rank test and Cox proportional hazards regression model were employed to compare differences in overall survival between patients with various SNP genotypes. All statistical analyses were performed using the SPSS version 17.0 (SPSS Inc., Chicago, IL). Survival time was defined as the time interval between the date of NSCLC diagnosis and date of death or last follow-up (August 20, 2013).

\section{Results}

\section{Patient Data and Clinicopathological Features}

The study included 542 NSCLC cases. The average age of these patients was 60 years, ranging from 34 to 80 years. Detailed characteristics of the study population are shown in Table 1. We conducted prospective follow-up on these patients. Up to August 20, 2013, a total of 517 patients completed follow-up, and 25 patients lost to follow-up. The rate of 
Table 1 Clinicopathological characteristics of patients

\begin{tabular}{|c|c|c|}
\hline Variable & $N=542$ & $\%$ \\
\hline \multicolumn{3}{|l|}{ Age } \\
\hline$<60$ & 272 & 50.2 \\
\hline$\geq 60$ & 270 & 49.8 \\
\hline \multicolumn{3}{|l|}{ Gender } \\
\hline Male & 344 & 63.5 \\
\hline Female & 198 & 36.5 \\
\hline \multicolumn{3}{|l|}{$\mathrm{BMI}^{\mathrm{a}}$} \\
\hline$<24$ & 254 & 47.4 \\
\hline$\geq 24$ & 282 & 52.6 \\
\hline \multicolumn{3}{|l|}{ Pathology } \\
\hline $\mathrm{SCC}$ & 282 & 52.0 \\
\hline $\mathrm{ADC}$ & 260 & 48.0 \\
\hline \multicolumn{3}{|c|}{ Chemotherapy } \\
\hline No & 246 & 45.4 \\
\hline Yes & 296 & 54.6 \\
\hline \multicolumn{3}{|c|}{ Clinical stages } \\
\hline $\mathrm{I}+\mathrm{II}$ & 346 & 63.8 \\
\hline $\mathrm{III}+\mathrm{IV}$ & 196 & 36.2 \\
\hline \multicolumn{3}{|c|}{ Tumor size $^{\mathrm{a}}$} \\
\hline$\leq 3$ & 222 & 41.2 \\
\hline$>3$ & 317 & 58.8 \\
\hline \multicolumn{3}{|c|}{$\mathrm{LN}_{\text {metastasis }}{ }^{\mathrm{a}}$} \\
\hline No & 301 & 57.6 \\
\hline Yes & 222 & 42.4 \\
\hline \multicolumn{3}{|c|}{ Distant metastasis } \\
\hline No & 498 & 91.9 \\
\hline Yes & 44 & 8.1 \\
\hline \multicolumn{3}{|l|}{ Death } \\
\hline No & 264 & 48.7 \\
\hline Yes & 278 & 51.3 \\
\hline
\end{tabular}

a Due to the missing value exists, the number of cases is less than 542 cases

loss to follow-up was $4.61 \%$. A total of 278 patients (51.3\%) died at the end of follow-up.

\section{Associations of SNPs with Lung Cancer Survival}

Results of univariate and multivariate survival analyses on SNP's associations with lung cancer survival are shown in Table 2. Of the 9 SNPs analyzed, only SNP rs10741657 in CYP2R1 was significantly associated with overall survival. Patients with homozygous variant genotype had over $64 \%$ longer median survival time than those with homozygous wild genotype $(P=0.033)$. This association remained significant after age, gender, tumor histology, postoperative chemotherapy and disease stage were adjusted in the analysis, the risk

reduction for death was more than $30 \%$ (adjusted $\mathrm{HR}=0.69$, 95\% CI: 0.46-0.97).

\section{Subgroup Analysis of SNP rs10741657 and Others}

To control for potential confounding effects, we performed additional survival analyses in subgroups of patients stratified by gender, age, histological type, disease stage and chemotherapy (Table 3). The subgroup analyses showed that the improved survival time in association with the variant genotype of rs10741657, AA or GA, mainly occurred to older patients (Fig. 1a) or without postoperative chemotherapy (Fig. 1b). Adjusted by various factors, the protective effect of genotype 'AA' or 'GA' for NSCLC patients still showed in the older or without postoperative chemotherapy. Their adjusted HRs were 0.71 (95\% CI: 0.51-0.99) for older patients, and 0.65 (95\%CI: $0.45-0.95$ ) for those without chemotherapy, respectively.

\section{Discussion}

The development of lung cancer is known to be related to both environmental and genetic factors, SNPs play an important role in genetic susceptibility. Previously, we compared certain SNP genotypes in the VD pathway between NSCLC cases and controls, and found a few associated with lung cancer risk [10]. In this report, we analyzed the association of the VD related SNPs with NSCLC prognosis and found that CYP2R1 rs10741657 was associated with the overall survival of NSCLC.

SNP rs10741657 is located in the promoter region of the CYP2R1 gene. A study by Slater, N.A. et al. [13] showed that non-carriers of rs10741657 risk alleles (CG) had higher levels of 25(OH)D. Ramos-Lopez et al. [12] found a significant association between the genotype of rs 10741657 and serum 25(OH)D concentrations in 203 German diabetic patients. Two genome-wide association studies (GWAS) on genetic determinants of serum of vitamin D published in 2010 [14, 15] and found that rs 10741657 was significantly associated with 25(OH)D concentrations in 30,000 subjects of European descent from 15 cohorts or in 496 unrelated healthy Caucasian subjects. Lasky-Su et al. [16] conducted a combined analysis of 1164 subjects from two cohorts of Caucasian and Costa Rica asthmatic children, and found that rs10741657 was significantly associated with $25(\mathrm{OH}) \mathrm{D}$ concentrations.

Ramos-Lopez etc. [12] studied the correlation between $25(\mathrm{OH}) \mathrm{D}_{3}$ and CYP2R1 mRNA with the genotypes of rs10741657, and reported that subjects carrying the 'GG' or 'GA' genotype of rs10741657 possessed, on average, lower levels of $25(\mathrm{OH}) \mathrm{D}_{3}$ compared to those with the 'AA' genotype. Others found that rs 10741657 was related to pancreatic cancer and glioma pathogenesis $[17,18]$. In our study, we found that CYP2R1 rs10741657 was related to the prognosis 
Table 2 Association of SNP on the VD metabolic pathways and NSCLC survival

\begin{tabular}{|c|c|c|c|c|c|}
\hline Genotype & $\begin{array}{l}\text { Case } \\
n=542\end{array}$ & $\begin{array}{l}\text { Death } \\
n=278\end{array}$ & $\begin{array}{l}\text { MST } \\
\text { (month) }\end{array}$ & Log-rank P & $\operatorname{HR}^{\mathrm{a}}(95 \% \mathrm{CI})$ \\
\hline \multicolumn{4}{|c|}{ CYP27B1(rs3782130) } & 0.263 & \\
\hline $\mathrm{CC}$ & 208 & 107 & 58.7 & & 1.00 \\
\hline CG & 262 & 129 & 58.2 & & $0.63(0.22-1.77)$ \\
\hline GG & 72 & 42 & 43.7 & & $1.16(0.33-4.18)$ \\
\hline \multicolumn{4}{|c|}{ CYP27B1(rs4646536) } & 0.625 & \\
\hline $\mathrm{CC}$ & 204 & 103 & 63.8 & & 1.00 \\
\hline $\mathrm{CT}$ & 172 & 85 & 56.0 & & $1.42(0.73-2.74)$ \\
\hline TT & 166 & 90 & 52.4 & & $1.43(0.68-3.04)$ \\
\hline \multicolumn{4}{|c|}{ CYP27B1(rs703842) } & 0.627 & \\
\hline $\mathrm{CC}$ & 214 & 109 & 63.8 & & 1.00 \\
\hline CT & 232 & 116 & 56.0 & & $1.27(0.67-3.25)$ \\
\hline TT & 96 & 53 & 57.6 & & $1.16(0.45-2.78)$ \\
\hline \multicolumn{4}{|c|}{ CYP27B1(rs10877012) } & 0.695 & \\
\hline TT & 213 & 109 & 58.7 & & 1.00 \\
\hline TG & 239 & 120 & 56.0 & & $1.28(0.69-1.97)$ \\
\hline GG & 89 & 48 & 51.5 & & $1.39(0.38-1.85)$ \\
\hline \multicolumn{4}{|c|}{ CYP24A1(rs6068816) } & 0.072 & \\
\hline $\mathrm{CC}$ & 191 & 89 & 68.2 & & 1.00 \\
\hline CT & 285 & 161 & 48.1 & & $1.13(0.86-1.49)$ \\
\hline TT & 66 & 28 & $77.4^{\mathrm{b}}$ & & $0.76(0.49-1.19)$ \\
\hline \multicolumn{4}{|c|}{ CYP24A1(rs4809957) } & 0.790 & \\
\hline GG & 210 & 103 & 63.8 & & 1.00 \\
\hline GA & 279 & 149 & 55.3 & & $0.97(0.74-1.26)$ \\
\hline AA & 53 & 26 & 50.9 & & $0.92(0.58-1.45)$ \\
\hline \multicolumn{4}{|c|}{ VDR(rs11574129) } & 0.050 & \\
\hline TT & 301 & 164 & 52.2 & & 1.00 \\
\hline $\mathrm{TC}$ & 231 & 107 & 75.2 & & $0.85(0.66-1.09)$ \\
\hline $\mathrm{CC}$ & 10 & 7 & 17.5 & & $1.44(0.66-3.11)$ \\
\hline \multicolumn{4}{|c|}{ GC(rs7041) } & 0.693 & \\
\hline TT & 297 & 157 & 52.7 & & 1.00 \\
\hline TG & 213 & 104 & 65.2 & & $0.82(0.64-1.07)$ \\
\hline GG & 32 & 17 & 43.6 & & $1.13(0.67-1.92)$ \\
\hline \multicolumn{4}{|c|}{ CYP2R1(rs10741657) } & 0.033 & \\
\hline GG & 221 & 125 & 50.9 & & 1.00 \\
\hline GA & 249 & 124 & 58.9 & & $0.79(0.61-1.03)$ \\
\hline AA & 71 & 28 & $79.5^{\mathrm{b}}$ & & $0.69(0.46-0.97)$ \\
\hline
\end{tabular}

${ }^{\mathrm{a}}$ Adjusted by gender, age, pathological diagnosis, postoperative chemotherapy, clinical stages; ${ }^{\mathrm{b}}$ Expression with an average survival time when the median survival cannot be calculated; Bold text highlights statistically significant findings

of lung cancer, and the 'AA' genotype was associated with reduced risk of NSCLC death. We also noticed that rs 10741657 'AA' alleles was the protective effect of CYP2R1 more evident in elderly patients without postoperative chemotherapy.

The CYP2R1 gene is located on chromosome 11p15.2, and spans about $15.5 \mathrm{~kb}$ with 5 exons, CYP2R1 is the key enzyme that converts vitamin $\mathrm{D}$ precusor to $25(\mathrm{OH}) \mathrm{D}$ in the liver [19]. In the patient with low circulating levels of $25(\mathrm{OH}) \mathrm{D}_{3}$ and symptoms of vitamin D deficiency, a study found a transition mutation in exon 2 of the CYP2R1 gene was found, which leads to the substitution of Proline Leucine at amino acid 99 in the CYP2R1 protein and abolishes enzymatic activity of vitamin D 25-hydroxylase, indicating that genetic variation in this gene can affect 25(OH)D synthesis [20].

Research on lung cancer risk and disease progression is often related. The aim of this study is to examine the relationship between the VD pathway-related SNPs and the prognosis of 
Table 3 The stratified analysis of CYP2R1 rs10741657 and prognosis of NSCLC

\begin{tabular}{|c|c|c|c|c|c|c|}
\hline \multirow[t]{2}{*}{ Variable } & \multicolumn{2}{|c|}{ Case/Death } & \multicolumn{2}{|c|}{ MST (month) } & \multirow[t]{2}{*}{ Log-rank P } & \multirow[t]{2}{*}{$\mathrm{HR}^{\mathrm{a}}(95 \% \mathrm{CI})$} \\
\hline & GG & $\mathrm{GA}+\mathrm{AA}$ & GG & $\mathrm{GA}+\mathrm{AA}$ & & \\
\hline \multicolumn{7}{|l|}{ Gender } \\
\hline Male & $139 / 82$ & $204 / 99$ & 50.5 & 68.2 & 0.064 & $0.79(0.59-1.06)$ \\
\hline Female & $82 / 43$ & $116 / 53$ & 50.9 & 68.7 & 0.334 & $0.77(0.51-1.15)$ \\
\hline \multicolumn{7}{|l|}{ Age } \\
\hline$<60$ & $108 / 55$ & $164 / 75$ & 62.7 & 68.7 & 0.672 & $0.91(0.64-1.29)$ \\
\hline$\geq 60$ & $113 / 70$ & $156 / 77$ & 28.3 & 68.2 & 0.014 & $0.71(0.51-0.99)$ \\
\hline \multicolumn{7}{|l|}{ Pathology } \\
\hline SQCC & $117 / 67$ & $165 / 85$ & 51.7 & 58.9 & 0.279 & $0.83(0.60-1.14)$ \\
\hline $\mathrm{ADC}$ & $104 / 58$ & $155 / 67$ & 49.1 & - & 0.054 & $0.74(0.52-1.06)$ \\
\hline \multicolumn{7}{|l|}{ Stage } \\
\hline $\mathrm{I}+\mathrm{II}$ & $137 / 57$ & $209 / 69$ & - & - & 0.131 & $0.77(0.54-1.09)$ \\
\hline $\mathrm{III}+\mathrm{IV}$ & $84 / 68$ & $111 / 83$ & 22.7 & 27.8 & 0.181 & $0.82(0.60-1.14)$ \\
\hline \multicolumn{7}{|c|}{ Chemotherapy } \\
\hline No & $99 / 56$ & $147 / 55$ & 45.7 & - & 0.002 & $0.65(0.45-0.95)$ \\
\hline Yes & $122 / 69$ & $173 / 97$ & 51.7 & 46.4 & 0.997 & $0.94(0.69-1.28)$ \\
\hline
\end{tabular}

${ }^{a}$ Adjusted by age, gender, pathological diagnosis, clinical stage and postoperative chemotherapy; Bold text highlights statistically significant findings
NSCLC. In our previous study we discussed the association between genetic polymorphism and lung cancer risk [10]. Although there have been a lot of studies investigating VD association with lung cancer prognosis, it is the first study to assess the genetypes of various VD-related genes is association with NSCLC prognosis.

Recent studies suggest a possible association between lung cancer development and VD concentration. In 2007, Mohr et al. [21] studied the incidence of lung cancer in 111 countries, and found that ultraviolet radiation (UV) exposure was associated with the incidence of lung cancer. Large survival studies from Norway and England showed that lung cancer patients diagnosed in summer or autumn had longer survival than those diagnosed in winter, suggesting that UV exposure maybe related to lung cancer outcome $[22,23]$. Zhou et al.
[24] studied 456 NSCLC patients in relation to season of surgery and VD intake. The study found that patients operated in summer and with high VD intake had better 5-year survival and longer overall survival than those operated in winter and with low VD intake. The 5 year survival rates were $56 \%$ versus $23 \%$, respectively. Another study in which 447 early stage NSCLC patients were analyzed for their serum $25(\mathrm{OH})$ $\mathrm{D}$, found that serum levels of $25(\mathrm{OH}) \mathrm{D}$ and VD intake were association with the overall survival of NSCLC patients with stage IB-IIB disease. Levels of $1,25(\mathrm{OH})_{2} \mathrm{D}_{3}$ were positively correlated with overall survival time. Patients with $1,25(\mathrm{OH})_{2} \mathrm{D}_{3}>21.6 \mathrm{ng} / \mathrm{ml}$ had $26 \%$ increase in survival compared to those that $1,25(\mathrm{OH})_{2} \mathrm{D}_{3}<10.2 \mathrm{ng} / \mathrm{ml}$ [25]. Tretli et al. [26] also confirmed that high serum $25(\mathrm{OH})$ D levels was associated with good prognosis of lung cancer.
Fig. 1 Kaplan-Meier plot of overall survival curves according to CYP2R1 rs10741657G > A genotype in older patients (a), and patients without postoperative chemotherapy $(\mathbf{b})$
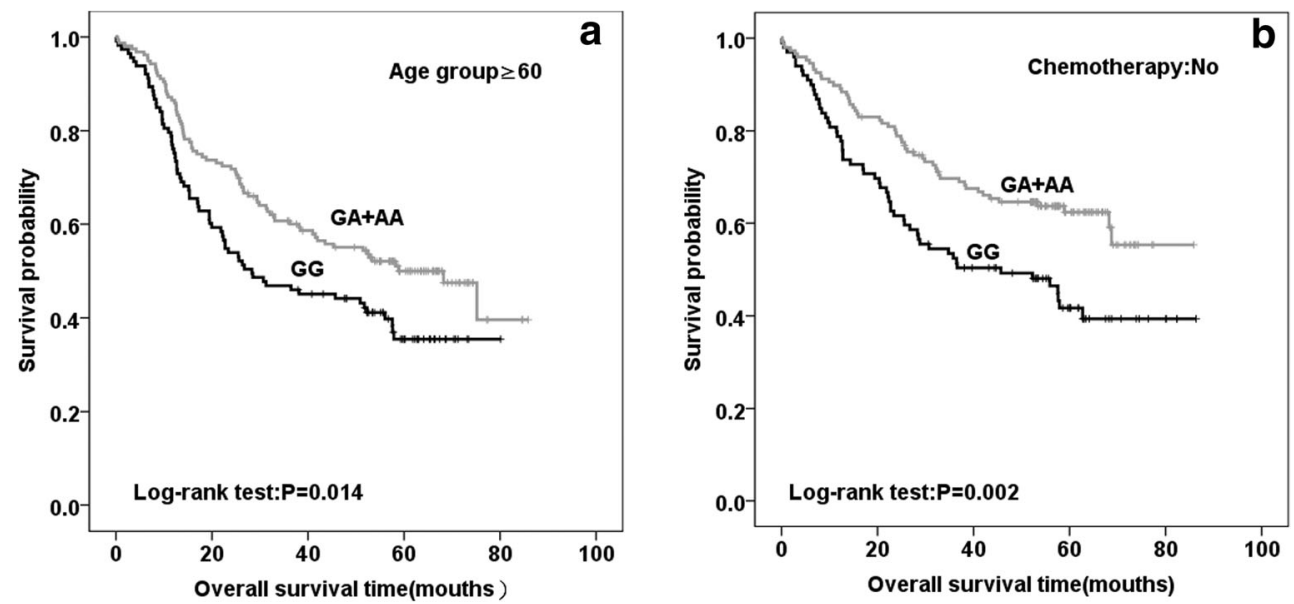
Genetic polymorphisms have been suspected to partially drive host susceptibility to lung cancer, as well as variations in therapeutic response and prognosis. Our study found a genetic polymorphism in the VD pathway associated with NSCLC prognosis. This finding provides evidence for VD's link the tumor progression and suggests the possibility that VD may have the therapeutic potential. However, our observation needs further confirmation from independent studies. The prognosis of lung cancer is influenced by many factors, such as histological type, disease state, age at diagnosis, smoking status, sensitivity to chemotherapy drugs or radiation. Genetic polymorphisms may affect some of these factors. Our findings of gene polymorphisms in the VD pathway in relation to NSCLC prognosis is an example of such influences. Studies are also needed to elucidate the mechanisms of CYP2R1 rs10741657 in relation to the prognosis of NSCLC. Through additional studies, we will understand better the role of VD in lung cancer in development and progression.

\section{Conclusions}

This study showed that SNP rs10741657 in the CYP2R1 gene was associated with the risk of NSCLC death, especially in elderly NSCLC patients, and not being treated with chemotherapy. Some of the VD pathway-related genetic polymorphisms may influence the prognosis of NSCLC.

\begin{abstract}
Acknowledgments The authors thank all the study subjects for participating in this study as well as all volunteers for assisting in collecting the samples and data. B.Q. conceived and designed the study; J.K. and X.C performed the experiments, the contribution is equal; J.K., J.L., X.C. and J.W. analyzed the data and participated in the discussion; F.X. and M.G collected subjects and clinical data; B.Q., J.K., and H.Y. wrote and revised the manuscript. In addition, the authors thank the reviewers for their suggestions. All authors reviewed the manuscript. This study was financially supported by the National Natural Science Foundation of China (Grant No. 81573231), Natural Science Foundation of Shanghai (Grant No. 15ZR1424400), Translational Medicine Foundation of SJTU medical college (Grant No. 15ZH1001) and Medical and Health Project of Luoyang Science and Technology (Grant No.1603001A-5).
\end{abstract}

\section{Compliance with Ethical Standards}

Conflict of Interest No potential conflicts of interest were disclosed.

Open Access This article is distributed under the terms of the Creative Commons Attribution 4.0 International License (http:// creativecommons.org/licenses/by/4.0/), which permits unrestricted use, distribution, and reproduction in any medium, provided you give appropriate credit to the original author(s) and the source, provide a link to the Creative Commons license, and indicate if changes were made.

\section{References}

1. Spiro SG, Silvestri GA (2005) One hundred years of lung cancer. Am J Respir Crit Care Med 172:523-529. https://doi.org/10.1164/ rccm.200504-531OE

2. Jemal A, Bray F, Center MM, Ferlay J, Ward E, Forman D (2011) Global cancer statistics. CA Cancer J Clin 61:69-90. https://doi. org/10.3322/caac.20107

3. Siegel R, Naishadham D, Jemal A (2013) Cancer statistics,2013. CA Cancer J Clin 63:11-30. https://doi.org/10.3322/caac.21166

4. Borczuk AC, Gorenstein L, Walter KL, Assaad AA, Wang L, Powell CA (2003) Non-small cell lung cancer molecular signatures recapitulate lung developmental pathways. Am J Pathol 163:1949 1960. https://doi.org/10.1016/S0002-9440(10)63553-5

5. Nakagawa K, Kawaura A, Kato S, Takeda E, Okano T (2005) 1 alpha,25-Dihydroxyvitamin $\mathrm{D}(3)$ is a preventive factor in the metastasis of lung cancer. Carcinogenesis 26:429-440. https://doi.org/ 10.1093/carcin/bgh332

6. Bouillon R, Eelen G, Verlinden L, Mathieu C, Carmeliet G, Verstuyf A (2006) Vitamin D and cancer. J Steroid Biochem Mol Biol 102:156-162. https://doi.org/10.1016/j.jsbmb.2006.09.014

7. Ordonez-Moran P, Larriba MJ, Pendas-Franco N, Aguilera O, Gonzalez-Sancho JM, Munoz A (2005) Vitamin D and cancer: an update of in vitro and in vivo data. Front Biosci 10:2723-2749

8. Zhou W, Heist RS, Liu G et al (2006) Polymorphisms of vitamin D receptor and survival in early-stage non-small cell lung cancer patients. Cancer Epidemiol Biomark Prev 15:2239-2245. https://doi. org/10.1158/1055-9965.EPI-06-0023

9. Ali MM, Vaidya V (2007) Vitamin D and cancer. J Cancer Res Ther 3:225-230. https://doi.org/10.4103/0973-1482.87006

10. Kong J, Xu F, Qu J, Wang Y, Gao M, Yu H, Qian B (2015) Genetic polymorphisms in the vitamin $\mathrm{D}$ pathway in relation to lung cancer risk and survival. Oncotarget 6:2573-2582. https://doi.org/10. 18632/oncotarget.2951

11. Dong J, Hu Z, Wu C et al (2012) Association analyses identify multiple new lung cancer susceptibility loci and their interactions with smoking in the Chinese population. Nat Genet 44:895-899. https://doi.org/10.1038/ng.2351

12. Ramos-Lopez E, Bruck P, Jansen T, Herwig J, Badenhoop K (2007) CYP2R1 (vitamin D 25-hydroxylase) gene is associated with susceptibility to type 1 diabetes and vitamin D levels in Germans. Diabetes Metab Res Rev 23:631-636. https://doi.org/10.1002/ dmrr.719

13. Slater NA, Rager ML, Havrda DE, Harralson AF (2017) Genetic variation in CYP2R1 and GC genes associated with V itamin D deficiency status. J Pharm Pract 30:31-36. https://doi.org/10. 1177/0897190015585876

14. Wang TJ, Zhang F, Richards JB et al (2010) Common genetic determinants of vitamin D insufficiency: a genome-wide association study. Lancet 376:180-188. https://doi.org/10.1016/S01406736(10)60588-0

15. Bu FX, Armas L, Lappe J, Zhou Y, Gao G, Wang HW, Recker R, Zhao LJ (2010) Comprehensive association analysis of nine candidate genes with serum 25-hydroxy vitamin D levels among healthy Caucasian subjects. Hum Genet 128:549-556. https://doi.org/10. 1007/s00439-010-0881-9

16. Lasky-Su J, Lange N, Brehm JM et al (2012) Genome-wide association analysis of circulating vitamin D levels in children with asthma. Hum Genet 131:1495-1505. https://doi.org/10.1007/ s00439-012-1185-Z

17. Anic GM, Thompson RC, Nabors LB et al (2012) An exploratory analysis of common genetic variants in the vitamin D pathway including genome-wide associated variants in relation to glioma 
risk and outcome. Cancer Causes Control 23:1443-1449. https:// doi.org/10.1007/s10552-012-0018-7

18. Anderson LN, Cotterchio M, Knight JA, Borgida A, Gallinger S, Cleary SP (2013) Genetic variants in vitamin d pathway genes and risk of pancreas cancer; results from a population-based case-control study in Ontario, Canada. PLoS One 8:e66768. https://doi.org/ 10.1371/journal.pone.0066768

19. Cheng JB, Levine MA, Bell NH, Mangelsdorf DJ, Russell DW (2004) Genetic evidence that the human CYP2R1 enzyme is a key vitamin D 25-hydroxylase. Proc Natl Acad Sci U S A 101: 7711-7715. https://doi.org/10.1073/pnas.0402490101

20. Nissen J, Rasmussen LB, Ravn-Haren G et al (2014) Common variants in CYP2R1 and GC genes predict vitamin D concentrations in healthy Danish children and adults. PLoS One 9:e89907. https://doi.org/10.1371/journal.pone.0089907

21. Mohr SB, Garland CF, Gorham ED, Grant WB, Garland FC (2008) Could ultraviolet B irradiance and vitamin D be associated with lower incidence rates of lung cancer? J Epidemiol Community Health 62:69-74. https://doi.org/10.1136/jech.2006.052571

22. Porojnicu AC, Robsahm TE, Dahlback A, Berg JP, Christiani D, Bruland OS, Moan J (2007) Seasonal and geographical variations in lung cancer prognosis in Norway. Does vitamin D from the sun play a role? Lung Cancer 55:263-270. https://doi.org/10.1016/j. lungcan.2006.11.013
23. Lim HS, Roychoudhuri R, Peto J, Schwartz G, Baade P, Moller H (2006) Cancer survival is dependent on season of diagnosis and sunlight exposure. Int J Cancer 119:1530-1536. https://doi.org/10. 1002/ijc. 22052

24. Zhou W, Suk R, Liu G et al (2005) Vitamin D is associated with improved survival in early-stage non-small cell lung cancer patients. Cancer Epidemiol Biomark Prev 14:2303-2309. https://doi. org/10.1158/1055-9965.EPI-05-0335

25. Zhou W, Heist RS, Liu G et al (2007) Circulating 25hydroxyvitamin D levels predict survival in early-stage nonsmall-cell lung cancer patients. J Clin Oncol 25:479-485. https:// doi.org/10.1200/JCO.2006.07.5358

26. Tretli S, Schwartz GG, Torjesen PA, Robsahm TE (2012) Serum levels of 25-hydroxyvitamin D and survival in Norwegian patients with cancer of breast, colon, lung, and lymphoma: a populationbased study. Cancer Causes Control 23:363-370. https://doi.org/10. 1007/s10552-011-9885-6

Publisher's Note Springer Nature remains neutral with regard to jurisdictional claims in published maps and institutional affiliations. 